\title{
LLTI and Facebook Group Highlights
}

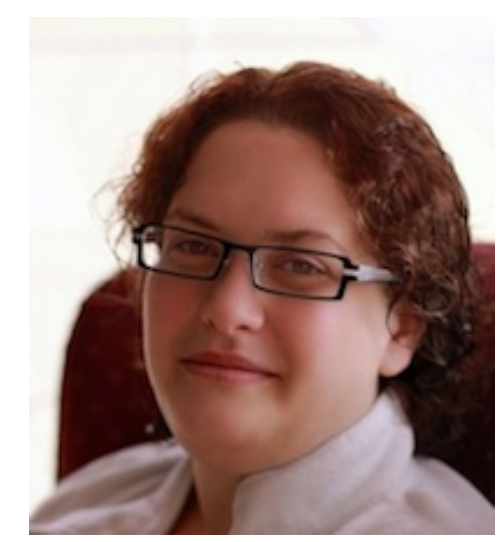

Deanne Cobb-Zygadlo

Kutztown University of Pennsylvania

This column marks an interesting change in the history of LLTI and IALLT member communications, and I am interested in whether or not the pattern continues in the future. In the past year, we have seen a steady reduction in the use of LLTI for questions pertaining to language learning technology or administration. The majority of posts on LLTI were instead job postings, calls for paper, conference announcements, and opportunities for professional development. All of these were useful postings, but more informational as opposed to professional exchanges. This lack of LLTI exchanges doesn't mean that IALLT members have stopped collaborating and sharing with their peers, but it does show the impact that social media has had on our organization. That is because the questions and sharing of resources that used to happen on the LLTI listserv has increasingly shifted to the IALLT Facebook group. 


\section{LLTI CONVERSATIONS}

There were still the occasional conversations that occurred via LLTI.

- Region-free VHS machines (\#10218): Jeremiah Spoon (Hamilton Collage) inquired after region-free VHS machines which not only offered some solutions but spurred some conversation about PAL, NTSC and SECAM formats (because really only DVDs have regions), as well as the quality of video produced by each and the best ways to convert, digitize or display the video, with the reduction in quality an issue in conversion.

- E-Portfolios (\#10212): Edwige Simon (University of Colorado at Boulder) asked for examples of e-portfolios that she could use in a workshop presentation and received suggestions that she look at the European Language Portfolio (ELP, http://eelp.gap.it), at the Lafayette Language Portfolios (http: //sites.lafayette.edu/fllrc/teachinglearning/eportfolio/) and at LinguaFolio at CASLS (http://casls.uoregon.edu/pages/tools/linguafolio.php).

- Noise-cancelling headsets (\#10210): Margo Burns (St. Paul's School) requested help with finding headsets that would block out ambient noise in a language lab and received two recommendations for the Sanako SLH-07 headset, but then on the other hand, a Robotel rep, Gerry Sullivan noted that what is needed in "noise-cancelling headsets" for a language lab is not only noise-cancelling ear cups but also a microphone that will not be sensitive to room noise, and he suggested the Robotel SC200-HS2 headset.

- Word for Mac and right-to-left text (\#10172): Judy Shoaf (University of Florida) sought a solution for producing a Word (for Mac) document in Hebrew that would maintain right-to-left order. This post spurred the most discussion including alternative word processor suggestions (Libra Office, Mellel, Mac Pages or Nisus Writer Pro), the suggestion that she create a template document in Windows Word 2010 with Hebrew as the base language and using this template document with Mac 2011 to create new Hebrew language documents and the suggestion that Judy's colleague use VMware to run a virtual Windows system so that he may use the Windows version of Microsoft Office.

- Virtual servers versus dedicated servers (\#10136): Stephen Shade (Guyer High School) asked for experienced information about dedicated versus virtual servers because he believed that issues they were having with their Sony Language Labs were likely related to their virtual servers. The Sans Inc. rep replied that the issue was likely due to how the virtual server was configured, and put him in touch with product support. 
Cobb-Zygadlo

- $\quad$ Adaptive computer test tools (\#10137): When Kellie Campbell (St. Michael's College) inquired after a tool for building computer-based tests for students worldwide with a specified number of test items / category that would be drawn randomly from a test bank, Concerto and LiveCode were both suggested as possible tools for developing such a test.

- Tandem Partner Website (\#10176): Sanja Miklin (University of Chicago PhD student) emailed that she was interested in developing a website that would arrange one-on-one language exchange meetings, that would be easy for groups of students who wish to practice languages to meet and announce meeting times / places, and that would act as a database of students to register as native speakers to help faculty with research projects requiring native speaker consultants. LLTI members recommended that she talk to Todd Bryant with Dickinson College about Mixxer, and that she look at UniCollaboration (http://unicollaboration.eu) and TandemPlus (https://tandem.umn.edu) as examples of similar products.

\section{FACEBOOK GROUP CONVERSATIONS}

Our Facebook Group is growing. I receive at least 2-3 new requests to join each week. Unlike LLTI posts which are moderated and which can take a few hours or even a day or two to be sent out to members, the Facebook group posts are visible immediately. This may be why this medium has become the more commonly utilized; however, from a communications management perspective, because not all members may be on Facebook (either because they prefer another social media platform or because their workplace discourages the use of social media), the use of this platform may have the unintended result of reducing the accessibility of posts for some, even while increasing the accessibility for others.

Many new tools were discussed and shared on Facebook since the end of December. You will notice that in referencing the Facebook group, I am leaving out names so as to reflect the fact that the group is a closed group and the posts made by individuals to the group are visible only to members of that group.

- Flipgrid (http://flipgrid.com) was raised as a potential tool for language teachers and language students. This tool was also featured in the December edition of the FLTMag (publication of the University of Colorado at Boulder).

- TouchCast (www.touchcast.com for iPads and PC desktop) was discussed as a video production tool. 
- Screenmailer for Mac (www.screenmailer.com) was discussed for its potential as a tool for flipped classroom materials preparation because of its screen recording and screencasting capabilities.

- Twitter Curator (https://chrome.google.com/webstore/detail/twittercurator/hodbfgbgmlpghbijbelkdmgjocohhhkp?hl=en) with Google docs was raised as a way to track student questions/posts in real time during class. Other alternative tools proposed for the same purpose were TodaysMeet (https://todaysmeet.com/) and Padlet (http://padlet.com/).

- A discussion ensued comparing the benefits and features of Socrative (www.socrative.com) and Kahoot! (https://getkahoot.com/).

- A query for inexpensive inventory tracking software yielded the suggestion of Bento (made by FileMaker), TapForms, and Delicious Library (version 2, not 3).

- An unsatisfied query was made for a cloud-based language learning software that can help intermediate / advanced learners refresh and enhance proficiency, particularly related to business, science and health topics.

- A second unsatisfied query was for anyone who had used TeamMates (http://teammatesv4.appspot.com/) or CATMe (info.catme.org) for peer assessments. The poster noted that TeamMates appeared to be quite easy given that her students already had Google accounts.

- A third unsatisfied query was for Automated Writing Evaluation (AWE) software for Spanish that would be similar to the ETS English language product Criterion.

- A fourth unsatisfied query was for anyone using the translation software $M e m o Q$ with students on campus.

Resource and research sharing also occurred via the Facebook group:

- One member successfully sought suggestions for fun, upbeat Asian Christmas tunes.

- Another member unsuccessfully sought suggestions for recent research articles, presentations, or conference proceedings that discusses the need for more teacher training and technology training. She noted that she was still using the 2007 MLA report, but hoped to locate more recent references.

- While a posting to the Facebook group for a partner class in a native Spanish-speaking country didn't yield a successful partnership via Facebook, the request was shared beyond the IALLT Facebook group by members, and the member searching for a partnership did form a partnership with another member of IALLT. 
Cobb-Zygadlo

Facebook group members also sought sage advice from their peers. These included inquiries about:

- the Wii language learning project at the University of Wisconsin - Eau Claire that was featured in the ACTFL Newsletter,

- best practices for using non-print, open-source textbooks such as Deutsch im Blick or Français interactif,

- experiences with NASILP programs,

- video-streaming services or media repositories as tools in the delivery of online film courses,

- what student workers should be required to call a new LRC Director,

- where LRC's are located on different campuses in relation to classrooms, language departments, library, writing center, etc.,

- what the first steps a new LRC Director should do upon arriving on campus.

Each of these inquiries was met with helpful advice and suggestions, as well as offers to connect the inquirers with others on campus who may have more information. In some cases, such as the location of LRC's on campus, the inquirer may need to talk with the respondents independently to determine how their LRC is used, and how the location has impacted who their users are and how the center is used. In other cases, very detailed responses were received, including suggestions such as resources that would be of great help. For instance, in regards to the questions about whether or not to insist student workers call the Director by their title or about what the first steps should be of a new LRC Director, in addition to a considerable amount of open discussion, the respondents recommended that the inquirer get not only the most recent edition of the IALLT Management Manual but also the previous edition because they each offered information that would be beneficial to an LRC Director new to the field.

In addition to these administrative and technical questions, there was also the kind of sharing that regularly occurs amongst peers and friends on Facebook. Members posted pictures, links, and news stories, which they thought other members of the group would find interesting. One story that was particularly interesting was a news video from Boston's NPR news station called "The Languages We're Learning Now" (http://onpoint.wbur.org/2014/01/13/foreignlanguages-chinese-economy). This article looked at how second language education has changed over the decades and what today's language education programs look like and need to look at to ensure the U.S.A.'s continued place in the global economy. 
The switch to relying more on social media for our professional collaborations and personal learning network does open up an interesting dilemma and it is one which I, as the Social Media Coordinator for IALLT, need to ponder in preparation for this Summer's Leadership Meeting,. This July, in preparation for the SLM, I need to submit to the Board a proposal of how I, as the Coordinator, will ensure open sharing of information between the organization and its members, how I will promote IALLT and regional group events, and how I will ensure an efficient and timely flow of communication from members on social media to the Board and Council as well. We, as a membership, also need to make decisions about our presence on the somewhat ubiquitous social media platforms, and how we can ensure sharing across those platforms as well. Do we have a Twitter username or a hashtag? Do we have a Google Community or keep our Google group? If we create a Facebook pageas the public face of IALLT to potential members, then does our Facebook group become a member-only group and how do we manage this? And of course, this also ties into conversations about member benefits and why our peers should be encouraged to become members of IALLT. Of course, debating these points is not the purpose of the column, but I did want to point out the relevance of this discussion and encourage all readers to join us for the Summer Leadership Meeting as we ponder our options as an organization, as well as so many other questions regarding IALLT and how the organization can best serve its membership. 